\title{
A UTILIZAÇÃO DE LABORATÓRIOS VIRTUAIS NO ENSINO DE QUÍMICA PARA A EDUCAÇÃO DE JOVENS E ADULTOS
}

\author{
Eduarda Fehlberg - eduardafehlberg@sapucaia.ifsul.edu.br- IFSUL \\ Graciela Vargas - graci_ela.vargas@hotmail.com - Uergs \\ Luciano Andreatta-da-Costa - luciano@uergs.edu.br - Uergs/Liberato
}

RESUMO: A Educação de Jovens e Adultos (EJA) difere do ensino regular devido ao seu público, porque traz consigo experiências de vida, pessoais e profissionais, que contribuem significativamente para a aprendizagem em sala de aula. Para o ensino de química, é essencial relacionar o prévio conhecimento e experiência com os conteúdos em sala de aula, especialmente na EJA. Nesta perspectiva, desenvolvemos uma atividade com o objetivo de melhorar os conceitos existentes no grupo e trabalhar com conteúdo químico chamado destilação, relacionando-a com questões relevantes para a vida diária. Os resultados obtidos nas avaliações dos alunos mostraram que a atividade proporcionou uma aprendizagem significativa de conceitos discutidos e uma reflexão sobre o uso responsável de álcool. A partir destes resultados, podemos concluir que a atividade foi eficiente e pode ser melhorada para contemplar novas discussões e reflexões.

Palavras-chave: Laboratórios virtuais; Educação em Ciências; Educação de Jovens e Adultos

\section{THE USE OF VIRTUAL LABS IN THE TEACHING OF CHEMISTRY FOR YOUTH AND ADULT EDUCATION}

\begin{abstract}
The Youth and Adult Education (EJA) differs from regular education due to your audience, because it carries with life experiences, personal and professional, which significantly contribute to learning in the classroom. For teaching chemistry, it is essential relate the prior knowledge and experience with the contents in the classroom, specilly in the EJA. In this perspective, we developed an activity with the aim of improving existing concepts in the group and work with chemical content called distillation, relating it to issues relevant to the daily life. The results obtained in student evaluations showed that the activity provided a meaningful learning of concepts discussed and a reflection on the responsible use of alcohol. From these results, we can conclude that the activity was efficient and can be enhanced to contemplate further discussions and reflections.
\end{abstract}

Keywords: Virtual Labs; Science Education; Youth and Adult Education 


\section{Introdução}

Esta pesquisa aborda prioritariamente dois temas que merecem um tratamento diferenciado: a Educação de Jovens e Adultos e o ensino de Química. Neste sentido, é relevante iniciar com o contexto atual destes temas.

\subsection{Contextualização da Educação de Jovens e Adultos}

A educação para jovens e adultos que não puderam, por diversas razões, completar seus estudos no tempo regular começou a ser pensada em meados do século XX pelo pernambucano Paulo Freire e pelo norte-rio-grandense Moacir de Góes, onde buscavam um ensino diferenciado para aqueles que retornavam à escola em busca de conhecimento. Freire e Góes acreditavam que o ensino deveria contemplar a necessidade daquele grupo de alunos e por esse motivo o desenvolvimento de um trabalho adequado para a faixa etária seria crucial (OLIVEIRA, 2007). Hoje, esses alunos, ao retornarem para a escola buscam sua inserção novamente na sociedade, por isso incentivar os mesmos a não abandonarem os estudos novamente é fundamental. $\mathrm{Na}$ maioria das vezes, esse grupo de estudantes são trabalhadores, buscando concluir aquilo que por algum motivo precisaram abrir mão no passado. Com isso, sua rotina se torna cansativa e superar as dificuldades físicas e intelectuais se torna desafiador.

Um problema que dificulta a superação dessas barreiras é não utilizar as experiências e os conhecimentos prévios dos alunos, mesmo que básicos, na condução das aulas. Esses alunos trazem em sua bagagem uma visão de mundo e sociedade que deve ser valorizada, dando significado aos conteúdos abordados em sala de aula, ou seja, mostrando aos mesmos a relação da sua experiência com os conceitos trabalhados (MUENCHEN e AULER, 2007). Associar suas experiências com as atividades desenvolvidas torna-se prazeroso e enriquecedor, tanto para o aluno quanto para o professor, fazendo com que o aluno tenha interesse em participar e expor sua percepção. Nesse sentido, Peluso (2003) afirma, que questões culturais costumam fragilizar a aprendizagem dos adultos, em intensidade bem maior que questões cognitivas

A percepção do aluno sobre a ligação direta dos conteúdos abordados com a sua vida poderá torná-lo mais ativo e autônomo em sala de aula, deixando de lado a timidez e a sensação de incapacidade. Ortiz menciona que o aluno da EJA precisa ver aplicação imediata daquilo que está aprendendo e também "desenvolver uma autoestima positiva (ORTIZ, 2002, p.80).

Diante de todas as variáveis relativas ao aluno da EJA, escolher a metodologia adequada para ser trabalhada em sala de aula é essencial e pode fazer com que o aluno tenha interesse em participar e contribuir com as suas experiências.

\subsection{A Educação de Jovens e Adultos e o ensino de Química}

O ensino de Química exige um nível de pensamento abstrato que acaba dificultando a compreensão dos alunos e quando trabalhado de forma isolada, acaba agravando ainda mais essa dificuldade de interpretação. Nesse sentido, abordar os 
conhecimentos prévios e temas do cotidiano do grupo de alunos pode facilitar o entendimento e as relações entre teoria e prática. Santos e Schnetzler (2003, p. 93) consideram que o objetivo central do ensino de Química para formar o cidadão é preparar o indivíduo para que ele compreenda e faça uso das informações químicas básicas necessárias para sua participação efetiva na sociedade tecnológica em que vive.

Entre as modalidades de ensino reconhecidas pelo Ministério da Educação está a Educação de Jovens e Adultos (EJA), a qual é composta por um grupo de alunos mais velhos que não concluíram seus estudos no tempo regular (BRASIL, 1996). Ensinar química para essa modalidade é tarefa árdua, pois em sua maioria são alunos desestimulados que enfrentam a escola depois de um longo dia de trabalho e problematizar o que será abordado em sala de aula pode ser um facilitador para o engajamento e interação dessa grupo. Nesse sentido, Delizoicov (1983, p.86) expressa que a problematização deve envolver questões do cotidiano, a partir de situações nas quais o educando se "confronta com situações de sua vida diária, desestabilizando seu conhecimento anterior e criando uma lacuna que o faz sentir falta daquilo que ele não sabe".

Essa problematização e a relação entre teoria e prática na ciência também estão citadas como uma das estratégias no Plano Nacional de Educação - PNE (BRASIL, 2014).

Pensando na formação de um cidadão, onde a criticidade e o questionamento são essenciais, Santos e Schnetzler (1996) destacam que a função do ensino de química deve ser a de desenvolver a capacidade de tomada de decisão, o que implica a necessidade de vinculação do conteúdo trabalhado com o contexto social em que o aluno está inserido.

\section{Fundamentação Teórica}

No contexto deste trabalho, é importante que sejam feitos alguns recortes em teorias de aprendizagem. Neste sentido, serão os tratados os temas geradores, o laboratório de aprendizagem virtual e a experimentação.

\subsection{Temas Geradores}

Segundo Paulo Freire (2005), trabalhar com a problematização de temas que se aproximam da realidade do educando faz com que o educador entenda melhor a realidade em que os seus alunos estão inseridos, facilitando aos mesmos observar o mundo que os cerca de maneira mais crítica e consciente. Nessa perspectiva, Freire menciona o trabalho com os chamados temas geradores.

Uma prática metodológica que associe o cotidiano dos alunos com os conteúdos abordados em sala de aula pode proporcionar uma maior interação entre aluno e professor, enriquecendo assim a aprendizagem. Nessa perspectiva, a contextualização do ensino de Química proporcionará que os alunos identifiquem os conceitos químicos presentes em seu cotidiano e que os questionem sob um ângulo científico (SANTOS e MORTINER, 1999). 


\subsection{Laboratório de Aprendizagem Virtual}

As novas tecnologias e o acesso rápido a qualquer informação que a internet disponibiliza estão desafiando o modelo tradicional de ensino, principalmente em química, trazendo questionamentos sobre a eficácia e o modo como o professor trabalha em sala de aula. Sobre o tema, Moran (2004) expressa os desafios presentes no ensinar e aprender, enfatizando que educar hoje é mais complexo devido a complexidade da própria sociedade.

Pensando nesse aspecto, as Tecnologias de Informação e Comunicação (TIC) surgem para contribuir com a reformulação da maneira de ensino-aprendizagem trabalhada no âmbito escolar, auxiliando os alunos na busca por novos conhecimentos. Com esse avanço, surgem os laboratórios de aprendizagem com o objetivo de facilitar e aperfeiçoar o processo de aprendizagem.

Segundo Schimitd e Tarouco (2008), os laboratórios de aprendizagem podem ser definidos em três modelos: presencial, remoto e virtual e os caracterizam como:

O laboratório presencial é aquele utilizado corriqueiramente em cursos presenciais, no qual o aluno manipula diretamente os materiais constitutivos dos experimentos, no mesmo espaço e tempo que seus colegas e na presença do professor. O laboratório remoto é aquele que se encontra distante do aluno

quando de sua utilização. Nesse tipo, a prática ocorre através de alguma interface que realiza a mediação entre o aluno $e$ os materiais $e$ equipamentos. Essa interface permite o controle à distância dos instrumentos e materiais reais que se encontram em lugar distinto daquele ocupado pelo aluno. Por último, o laboratório virtual é aquele baseado em simulações. $O$ aluno não interage com instrumentos e materiais reais, mas com representações computacionais da realidade. (SCHIMITD e TAROUCO, 2008)

Nesse sentido, AMARAL et al (2011) menciona que o uso dos laboratórios de aprendizagem tem se tornado mais frequentes, pois permite aos estudantes experimentar diferentes situações e potencializa a interação com o objeto.

Diante do uso intenso das tecnologias pelos alunos, tanto da EJA quanto do ensino regular, utilizá-la pode ser fator de motivação e curiosidade, onde os alunos aprenderão a manipular essas tecnologias em prol do conhecimento, aumentando a interação entre a ciência, a tecnologia e a sociedade. (Vieira et al, 2011)

\subsection{Experimentação}

Nas aulas de química, a experimentação obtém destaque aos olhos dos alunos por ser um ambiente onde podemos colocar em prática a teoria discutida em sala de aula. Para Izquierdo et al (1999), a experimentação demonstra princípios discutidos em sala de aula, investiga fenômenos na busca por aprimoramento e incentiva os alunos a discutirem, argumentarem e questionarem os efeitos dos experimentos, contribuindo significativamente com o aprendizado dos mesmos e ampliando a relação professor- aluno. 
Assis (2011) sugere que as aulas práticas devem servir de estratégia para $p$ professor retomar algum assunto anteriormente abordado.

Trabalhar com a experimentação significa criar um ambiente propício para a investigação, onde o aluno faça parte ativamente da construção da aprendizagem, onde ele investigue, analise, crie hipóteses, discuta e trabalhe em grupo, envolvendo-o na busca por conclusões que sustentem sua teoria (GUIMARÃES, 2009). Essa metodologia torna o ensino realmente ativo, envolvendo alunos na manipulação direta de materiais e na realização de experimentos onde eles possam modificá-los, testá-los e interpretá-los (MORAES e RAMOS, 1988).

\section{Metodologia}

No primeiro momento, foi solicitado aos alunos que respondessem um questionário eletrônico com o objetivo de avaliar os conhecimentos prévios dos mesmos a respeito do tema em discussão: destilação. O questionário era composto por 10 questões, das quais 07 foram objetivas de múltipla escolha e 3 questões dissertativas onde os alunos poderiam discorrer sobre seus conhecimentos, representando, segundoARROYO (2005), o "ponto de partida para uma pedagogia que se paute pelo diálogo entre os saberes escolares e sociais".

Logo após, houve um trabalho textual que trazia em seu conteúdo conceitos químicos sobre destilação e fermentação, e social com efeitos biológicos causados pelo consumo de álcool. Conforme MORAES (2008, p.3), “ na escola a aprendizagem se dá por reconstrução e complexificação do conhecimento que o aluno já traz para o contexto escolar”.

Depois da discussão do texto os alunos puderam, através do laboratório virtual disponível no endereço (http://www.pucrs.br/quimica/professores/arigony/lab.html), realizar virtualmente experimentos relacionados com o tema, acompanhar vídeos sobre a montagem dos aparelhos, acessar textos explicativos, além de um tutor que indicava os passos a serem seguidos na montagem dos aparelhos. O objetivo era fornecer aos alunos meios de trabalho seguro, sem a necessidade de um laboratório físico e sem preocupações com a disponibilidade de materiais, reagentes, além de horários para a realização da tarefa e assim permitir ao aluno trabalhar de forma autônoma e utilizando ferramentas diferenciadas, procurando-se "ajudar o educando a alcançar uma postura de reconhecimento social, através da qual ele mesmo consegue conquistar sua autoestima e autonomia individual "(FLICKINGER, 2011, p.11).

O segundo momento compreendeu a aula experimental em laboratório real (Figura 1), na qual foi proposta a realização do processo de destilação do vinho, conforme roteiro de prática entregue aos alunos. 


CINTED-UFRGS Novas Tecnologias na Educação

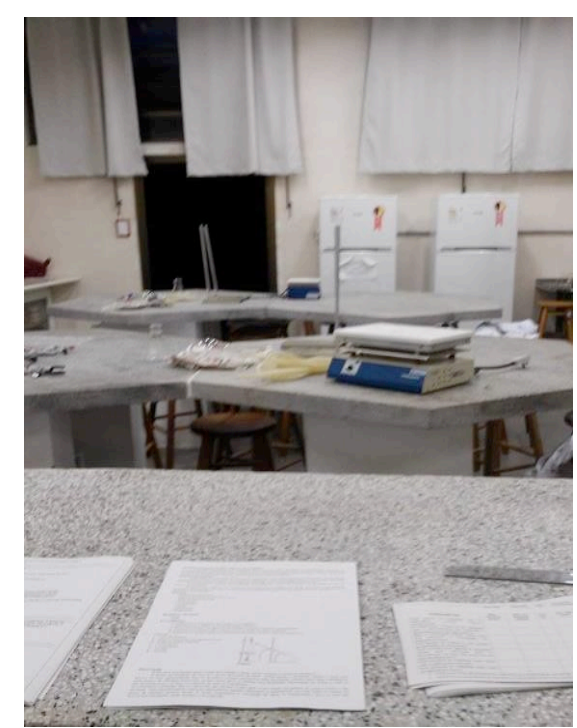

(a)

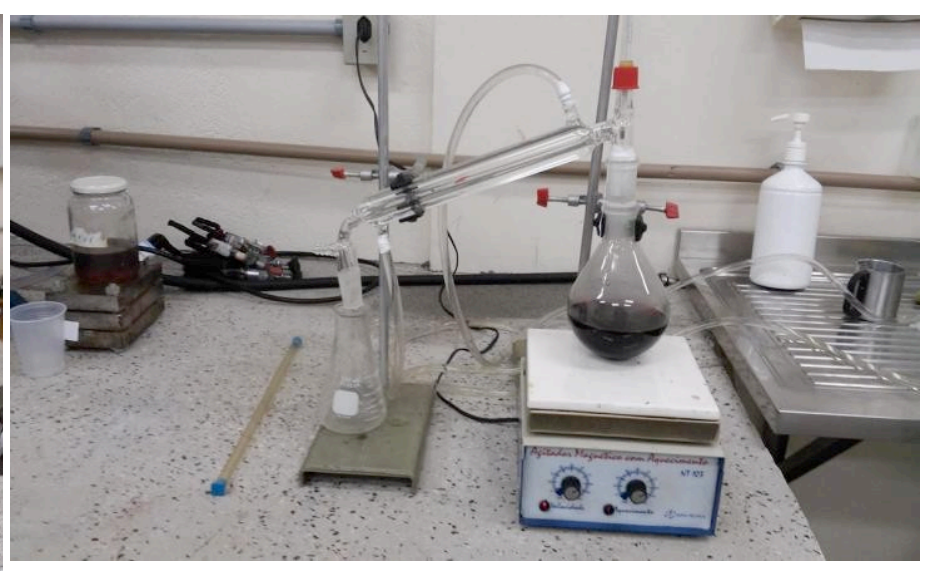

(b)

(a) Materiais dispostos para montagem (b) Processo de destilação

Figura 1 - Aula experimental em laboratório real

Para dar encaminhamento ao término das atividades foi desenvolvido um pós- teste, o qual era igual ao pré-teste, a fim de avaliar o processo de aprendizagem trabalhado e se o mesmo enriqueceu o conhecimento dos alunos, seguindo-se a definição da Educação de Adultos confirmada pela Conferência Internacional de Educação de Adultos (CONFINTEA VI), que estabelece que deve ser incluída "a educação não formal e toda a gama de oportunidades de aprendizagem informal e eventual que existem numa sociedade de aprendizagem multicultural" (UNESCO, 2010, p.5)

\section{Resultados e Discussões}

A atividade foi aplicada em uma turma de ensino técnico na modalidade EJA, em uma escola federal localizada na região metropolitana de Porto Alegre/RS.

Para avaliação foram desenvolvidos pré e pós-testes eletrônicos e também um questionário sobre as atividades realizadas. Os testes continham 10 questões cada, as quais eram compostas de 03 questões dissertativas e 07 de múltipla escolha. Em análise comparativa entre os dois momentos, foi possível avaliar a construção do conhecimento dos alunos e como os mesmos se sentiram durante as atividades propostas.

Sobre as questões dissertativas foi possível observar no pós-teste uma formulação de hipóteses muito mais complexa do que as realizadas no pré-teste, assim como um domínio de conceitos adquiridos durante o trabalho desenvolvido, como mostra o quadro comparativo (ver Quadro 1). 


\begin{tabular}{|c|c|}
\hline Pré-teste & Pós-teste \\
\hline $\begin{array}{l}\text { É o processo de separar certos elementos } \\
\text { na hora da fervura. Ex. Cachaça e } \\
\text { petróleo. }\end{array}$ & $\begin{array}{l}\text { É o processo de aquecimento do líquido e } \\
\text { após pelo resfriamento do vapor. }\end{array}$ \\
\hline $\begin{array}{l}\text { Eu acho que seria um processo de } \\
\text { fermentação em caldeiras. }\end{array}$ & $\begin{array}{l}\text { É o processo de separação de dois ou mais } \\
\text { líquidos que passa pelo aquecimento e após } \\
\text { resfriamentos. }\end{array}$ \\
\hline $\begin{array}{l}\text { Baixo teor, destilar passar várias vezes, } \\
\text { filtrar. }\end{array}$ & $\begin{array}{l}\text { Que ela é separada de uma mistura líquida } \\
\text { nos seus componentes por meio de fervura, seguida de } \\
\text { condensação do vapor. }\end{array}$ \\
\hline $\begin{array}{l}\text { Eu acho que é quando um líquido é } \\
\text { fervido, que depois evapora dentro de } \\
\text { outro. }\end{array}$ & $\begin{array}{l}\text { Modo de separar dois líquidos por } \\
\text { aquecimento e resfriamento na sequência. }\end{array}$ \\
\hline Separar elementos. & É um processo de separação dos líquidos. \\
\hline $\begin{array}{l}\text { Já ouvi falar na palavra, mas não recordo } \\
\text { o seu significado. }\end{array}$ & $\begin{array}{l}\text { Destilação é obtida através da fervura e } \\
\text { depois da condensação. }\end{array}$ \\
\hline É um líquido quente. & $\begin{array}{l}\text { A destilação é a separação de uma mistura } \\
\text { líquida nos seus componentes por meio de fervura } \\
\text { seguida da condensação do vapor. }\end{array}$ \\
\hline
\end{tabular}

Quadro 1: Respostas referentes ao questionamento "O QUE É DESTILAÇÃO?"

Conforme podemos observar no quadro acima, os alunos mostraram entendimento sobre o processo de destilação e como esse é realizado. Outro ponto que pode ser observado em sala de aula, tanto no momento do laboratório virtual quanto no físico, foi a interação entre os alunos e a forma como relacionavam o conteúdo com fatos e acontecimentos do seu cotidiano, contextualizando o objeto de estudo.

Para análise das questões fechadas, de múltipla escolha, foi escolhido o teste não-paramétrico de Wilcoxon (1945), procedimento o qual serve para amostras com até 100 indivíduos gerando a tabela a seguir:

\begin{tabular}{ccccc}
\hline Questões & $\begin{array}{c}\text { Pré- } \\
\text { teste }\end{array}$ & $\begin{array}{c}\text { Pós- } \\
\text { teste }\end{array}$ & d & Posto \\
\hline $\mathbf{1}$ & 11 & 16 & -5 & -5 \\
$\mathbf{2}$ & 6 & 17 & -11 & -6 \\
$\mathbf{3}$ & 8 & 20 & -12 & -1 \\
$\mathbf{4}$ & 5 & 18 & -13 & -2 \\
$\mathbf{5}$ & 20 & 19 & 1 & 3 \\
$\mathbf{6}$ & 20 & 22 & -2 & -4 \\
\hline $\mathbf{7}$ & 5 & 22 & -17 & -7 \\
\hline Total de & 75 & 134 & & \\
acertos & & & & \\
\hline
\end{tabular}

Quadro 2- Número de acertos no pré-teste e pósteste, e os dados do teste de Wilcoxon.

Com o teste da mediana, desenvolvido por F. Wilcoxon (1945), sobre duas amostras pertencentes a uma mesma população, foi possível constatar que no pós-teste houve uma ascendente de valores dos dados comparados ao pré-teste. Assim, foi observado que as atividades realizadas proporcionaram uma melhor compreensão dos 
conceitos sobre destilação bem como o processo envolvido na separação de líquidos pelo controle da temperatura.

Outro questionário avaliativo desenvolvido, com o fim de verificar se os alunos haviam aprovado o uso do Laboratório Virtual e da aula experimental, foi realizado seguindo a escala de cinco (5) pontos descritos por Likert (1932).

\begin{tabular}{|l|c|}
\hline \multicolumn{1}{|c|}{ Afirmação } & Média \\
\hline 1. Você gostou de trabalhar com o laboratório virtual? Achou interessante? & 4,526 \\
\hline $\begin{array}{l}\text { 2. O laboratório virtual foi de utilidade para o entendimento do } \\
\text { conteúdo e desenvolvimento da aula prática? }\end{array}$ & 4,578 \\
\hline $\begin{array}{l}\text { 3. Após montagem online, ficou mais fácil entender a montagem } \\
\text { no laboratório físico? }\end{array}$ & 4,315 \\
\hline $\begin{array}{l}\text { 4. Você gostou de realizar a aula prática da atividade em } \\
\text { discussão? }\end{array}$ & 4,578 \\
\hline $\begin{array}{l}\text { 5. Você acredita que apenas a atividade online seria suficiente para } \\
\text { o aprendizado, ou seja, não precisaria da aula do laboratório? }\end{array}$ & 1,684 \\
\hline $6 . \quad$ Você gostaria de trabalhar mais vezes com o laboratório virtual? & 4,368 \\
\hline 7. Você gostaria de trabalhar mais vezes no laboratório físico? & 4,631 \\
\hline
\end{tabular}

Quadro 3: Avaliação das metodologias utilizadas nas atividades.

Com a escala Likert foi possível observar que a maioria dos alunos mostrou satisfação em trabalhar com o laboratório de aprendizagem virtual e com a atividade de experimentação, gerando médias altas na escala. A grande parte do grupo de alunos achou interessante a atividade virtual e gostaria de trabalhar com a ferramenta mais vezes, porém não acreditam que a mesma possa substituir totalmente a atividade experimental e sim auxiliá-la.

\section{Considerações Finais}

A Educação de Jovens e Adultos (EJA) possui suas peculiaridades, pois é uma modalidade de ensino composta por um grupo que traz consigo as experiências vividas no seu cotidiano, o que é desafiador aos professores, pois há a necessidade de criar atividades significantes ao aluno, permitindo a interação entre o grupo e que esses possam trocar informações e experiências. Possibilitar uma aprendizagem significativa utilizando metodologias diferenciadas é uma das maneiras de motivar os alunos a participarem e a se desafiarem também, a fim de que as aulas não se tornem monótonas e pouco atrativas, mas sim motivadoras e incentivadoras na busca pelo conhecimento.

Para tornar a sala de aula mais incentivadora, a utilização de conceitos químicos contextualizados pode estabelecer um diálogo com a realidade dos alunos, superando a mera transmissão de conteúdos e se fazendo imprescindível, pois os alunos trazem consigo suas bagagens de vida e podem compartilhá-las. Neste sentido, ARROYO menciona que é fundamental se conhecer o perfil dos jovens e adultos educandos, enfatizando que destina-se muito pouca carga horária para se discutir a importância da inserção do conhecimento do educando nos programas de ensino. 
Desta forma, o trabalho promoveu uma reflexão dos alunos sobre a observação do cotidiano sob um olhar científico, promovendo a participação ativa do grupo e uma autonomia pela busca do conhecimento, utilizando ferramentas diferentes das cotidianamente implementadas na sala de aula.

\section{Referências Bibliográficas}

AMARAL, Érico et al. Laboratório Virtual de Aprendizagem: uma proposta taxonômica. Renote, v. 9, n. 2, 2011.

ARROYO, Miguel Gonzales. Educação de Jovens-Adultos: um campo de direitos e de responsabilidade pública. In: Leôncio Soares; Maria Amélia Giavanetti; Nilma Lino Gomes. (Org.). Diálogos na Educação de Jovens e Adultos. 1 ed. Belo Horizonte: Autêntica,2005.

ASSIS, Mariana da Silva. Experimentação como estratégia didática para o ensino de química na educação de jovens e adultos. Trabalho de conclusão de curso. UFRGS.2011

BRASIL. Lei nº 9.394, de 20 de dezembro de 1996.

BRASIL. Lei $\mathrm{n}^{\mathrm{o}}$ 13.005, de 25 de junho de 2014.

CALLEGARI-JACQUES, SIDIA M. Bioestatística: Princípios e Aplicações Porto Alegre: Artimed,2003.

MUENCHEN, Cristiane; AULER, Décio. Abordagem temática: desafios na educação de jovens e adultos. Revista Brasileira de Pesquisa em Educação em Ciências. v. 7, n. 3, 2007. ISSN 1806-5104.

DELIZOICOV, D. Ensino de física e a concepção freiriana de educação. Revista de Ensino de Física, v.5, n.2, p. 85-98, 1983.

FLICKINGER, H.G. Senhor e escravo: uma metáfora pedagógica. Revista de Educação AEC, Brasília: v. 29, n. 114, p. 11, jan./mar. 2000.

Freire, Paulo. Pedagogia do oprimido. Rio de Janeiro: Paz e Terra, 2005.

GUIMARÃES, Cleidson Carneiro. Experimentação no ensino de química: caminhos e descaminhos rumo à aprendizagem significativa. Química Nova na Escola, v. 31, n. 3, p. 198-202, 2009.

IZQUIERDO, M.; SANMARTÍ, N. e ESPINET, M. Fundamentación y diseño de las practicas escolares de ciências experimentales. Enseñanza de las Ciencias, v. 17, n. 1, p. 45-60, 1999. Apud DA SILVA GRACIANO, Marlene Ribeiro et al. A experimentação investigativa do tema ácido e baseno processo de ensino e aprendizagem da educação de jovens e adultos (EJA). Ciclo Revista, v. 1, n. $2,2016$. 
MORAES, R. A produção do conhecimento químico e o ensino de Química: movimentos entre o conhecimento cotidiano e o conhecimento químico. Mesa Redonda no XIV Encontro Nacional de Ensino de Química, Curitiba, 2008.

MORAES, Roque; RAMOS, Maurivan Guntzel. Construindo o conhecimento: uma abordagem para o ensino de ciências. Sagra, 1988.

MORAN, José Manuel. Os novos espaços de atuação do educador com as tecnologias. Conhecimento local e conhecimento universal: diversidade, mídias e tecnologias na educação. Curitiba: Champagnat, p. 245-253, 2004.

OLIVEIRA, I. B. de. Reflexões acerca da organização curricular e das práticas pedagógicas na EJA. Educar, Curitiba, n. 29, p. 83-100, 2007. Editora UFPR

ORTIZ, M. F. A. Educação de Jovens e Adultos: um estudo do nível operatório dos alunos. Dissertação de Mestrado. Universidade Estadual de Campinas. UNICAMP. 2002.

PELUSO, T.C.L. Diálogo \& Conscientização: alternativas pedagógicas nas políticas públicas d educação de jovens e adultos. Tese de Doutorado. Universidade Estadual de Campinas. UNICAMP. 2003.

SANTOS, W.L. ; MORTINER, E. F. A dimensão social do ensino de Química - Um estudo exploratório da visão de professores. In: II Encontro Nacional de pesquisa em Educação em Ciências. Valinhos, 1999. Atas em CD-Room. Apud: Letícia Gomes de Ávila. Soluções: uma proposta de ensino contextualizada para alunos da EJA. Porto Alegre, 2011. UFRGS. TRABALHO DE CONCLUSÃO DE CURSO.

SANTOS, W. L. P.; SCHNETZLER, P. R. Educação em Química: Compromisso com a Cidadania, 3 ed. Ijuí: Unijuí, 2003.

SANTOS, W.L.P; SCHNETZLER, R. P. Função Social: O que Significa o Ensino de

Química Para Formar Cidadãos? Química Nova na Escola. N. 4, novembro, pg.2834, 1996.

SCHIMIDT, Marcelo A. R.; TAROUCO, Liane M. R. Metaversos e laboratórios virtuais -possibilidades e dificuldades. Revista de Novas Tecnologias na Educação, Porto Alegre, v. 6, n. 1, p 1-12, jul/2008.

UNESCO. Marco de Ação de Belém. Conferência Internacional de Educação de Adultos - COFINTEA, VI., 2010, Brasília. Anais... Brasília: UNESCO-MEC, 2010.

VIEIRA, Eloisa; MEIRELLES, RMS; RODRIGUES, DCGA. O uso de tecnologias no ensino de química: a experiência do laboratório virtual química fácil. Encontro Nacional de Pesquisa em Educação em Ciências, v. 8, 2011. 